\title{
H2 LIVES!
}

\section{Dear Reader,}

hardly any other topic is more often the subject of controversial discussion in our industry than that of alternative drive systems and vehicle concepts. At the same time, there is no denying that reducing fuel consumption and $\mathrm{CO}_{2}$ emissions is of key importance against the background of the increasing burden that greenhouse gases are placing on our planet. It is therefore essential to develop new powertrain and vehicle concepts and above all to put them on our roads.

Electric cars are certainly a conceivable solution, even though their usage may still be severely restricted for some time due to their limited driving range. Like alternative fuels, various applications of downsizing and hybrid concepts will surely have much greater potential in the coming decade.

In all of these discussions, there is one concept that has tended to take a back seat in public perception in recent times, although it unquestionably has a promising future: the fuel cell. At the start of this millennium, the term was on everyone's lips. In meantime, the concept was already declared dead - too complicated, too expensive was the verdict. Now it is experiencing something of a renaissance as people start to realise that this concept is far superior to electric cars in terms of driving range. Of course, there is still the problem of cost, which has to be solved if fuel-cell vehicles are to be sold in more than merely homeopathic quantities and only for test purposes. But the concept itself makes sense and is ground-breaking.

For that reason, the main topic of ATZ 12 is also dedicated to this subject. For example, on page 4 this issue takes a detailed look at BMW's LOHC project, which deals with liquid hydrogen carri- ers as a future fuel for passenger cars. As infrastructure also play a major role in hydrogen drive systems, we examine this aspect from the point of view of the Clean Energy Partnership, in which manufacturers, distributors and hydrogen producers are working together. Last but not least, no consideration of alternative drive systems can ignore two-wheeled vehicles. In this means of transport - a good example is the Suzuki scooter presented on page 10 - alternative concepts can be implemented more cost-effectively and with a higher driving range than in cars.

The problem of hydrogen production from regenerative energy sources has been fundamentally solved. If one also considers what relevant amounts of hydrogen are also produced as a "waste product" in the production of chlorine alone, hydrogenpowered drive systems do indeed have a future.

Best regards,

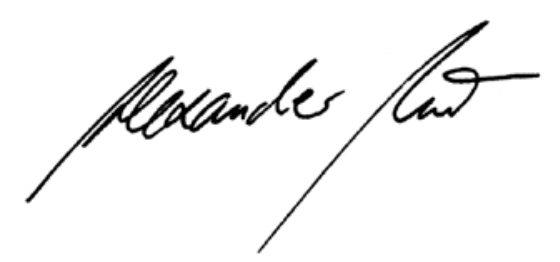

DR. ALEXANDER HEINTZEL, Editor in Chief Wiesbaden, 29 October 2012

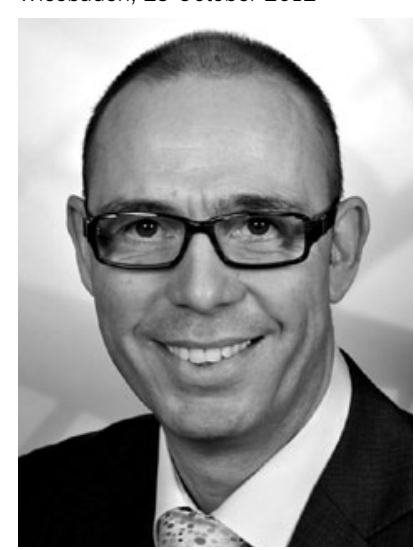

